Article

\title{
Investigation on Fabrication of Reduced Graphene Oxide-Sulfur Composite Cathodes for Li-S Battery via Hydrothermal and Thermal Reduction Methods
}

\author{
Zhiqi Li ${ }^{1}$, Hao Sun ${ }^{1}$, Yuepeng Pang ${ }^{1}$, Mingming Yu ${ }^{2, *}$ and Shiyou Zheng ${ }^{1, *}$ \\ 1 School of Materials Science and Engineering, University of Shanghai for Science and Technology, \\ Shanghai 200093, China; lizhiqiusst@163.com (Z.L.); sunhao@usst.edu.cn (H.S.); pangyp@usst.edu.cn (Y.P.) \\ 2 Research Center of Composite Materials, School of Materials Science and Engineering, Shanghai University, \\ Shanghai 200000, China \\ * Correspondence: mmyu@shu.edu.cn (M.Y.); syzheng@usst.edu.cn (S.Z.)
}

Citation: Li, Z.; Sun, H.; Pang, Y.; Yu, M.; Zheng, S. Investigation on Fabrication of Reduced Graphene Oxide-Sulfur Composite Cathodes for Li-S Battery via Hydrothermal and Thermal Reduction Methods. Materials 2021, 14, 861. https:// doi.org/10.3390/ma14040861

Academic Editor: Jean

François Drillet

Received: 8 January 2021

Accepted: 8 February 2021

Published: 11 February 2021

Publisher's Note: MDPI stays neutral with regard to jurisdictional claims in published maps and institutional affiliations.

Copyright: (c) 2021 by the authors. Licensee MDPI, Basel, Switzerland. This article is an open access article distributed under the terms and conditions of the Creative Commons Attribution (CC BY) license (https:// creativecommons.org/licenses/by/ $4.0 /)$.

\begin{abstract}
Lithium-sulfur (Li-S) battery is considered one of the possible alternatives for nextgeneration high energy batteries. However, its practical applications are still facing great challenges because of poor electronic conductivity, large volume change, and polysulfides dissolution inducing "shuttle reaction" for the S cathode. Many strategies have been explored to alleviate the aforementioned concerns. The most common approach is to embed $S$ into carbonaceous matrix for constructing C-S composite cathodes. Herein, we fabricate the C-S cathode reduced graphene oxide-S (rGO-S) composites via one step hydrothermal and in-situ thermal reduction methods. The structural features and electrochemical properties in Li-S cells of the two type rGO-S composites are studied systematically. The rGO-S composites prepared by one step hydrothermal method (rGO-S-HT) show relatively better comprehensive performance as compared with the ones by in-situ thermal reduction method (rGO-S-T). For instance, with a current density of $100 \mathrm{~mA} \mathrm{~g}^{-1}$, the rGO-S-HT composite cathodes possess an initial capacity of $1290 \mathrm{mAh} \mathrm{g}^{-1}$ and simultaneously exhibit stable cycling capability. In particular, as increasing the current density to $1.0 \mathrm{~A} \mathrm{~g}^{-1}$, the rGO-S-HT cathode retains a reversible capacity of $582 \mathrm{mAh} \mathrm{g}^{-1}$ even after 200 cycles. The enhanced electrochemical properties can be attributed to small S particles uniformly distributed on rGO sheets enabling to significantly improve the conductivity of $S$ and effectively buffer large volume change during lithiation/delithiation.
\end{abstract}

Keywords: reduced graphene oxide; sulfur; composite; battery; Li-S battery

\section{Introduction}

Lithium-sulfur (Li-S) batteries have a hopeful prospect among emerging battery systems because of their high specific capacity and energy density in theory [1-5]. Unfortunately, their practical realization suffers from low active material utilization and poor cycle life together with low Coulombic efficiency, which are mainly related to electrically insulating characteristics of $\mathrm{S}$ and its discharging products $\left(\mathrm{Li}_{2} \mathrm{~S}_{2}\right.$ and $\left.\mathrm{Li}_{2} \mathrm{~S}\right)$, solubility of the reaction intermediates polysulfides $\left(\mathrm{Li}_{2} \mathrm{~S} x, 3 \leq x \leq 8\right)$ in liquid electrolytes, shuttle reaction of dissolved lithium polysulfides, and large volume variation during lithiation/delithiation [6-10].

To alleviate the aforementioned problems, many research attempts have been conducted to design special structured materials in order to construct S-based cathodes, functional interlayers, hybrid electrolytes, and modified separators for Li-S batteries. The electrolytes with different additives have been recognized to enhance the stability of electrochemical reactions during charge and discharge process [11-13]. Some functional materials are adopted as interlayer or coated to separator, which could suppress shuttling reaction effectively [14-16]. Most of the research is dedicated to designing and constructing S-based cathode materials, focusing on loading the active material $S$ in a variety of matrix, such 
as carbon-based materials, conductive polymers, transition metal oxide, and $2 \mathrm{D} \mathrm{Ti}_{3} \mathrm{C}_{2} \mathrm{~T}_{\mathrm{x}}$ (MXenes), etc. [17-25]. The most common strategy is to embed $S$ into the carbonous matrix. Various carbon materials with different microstructures have been investigated to enhance the conductivity and simultaneously to prevent polysulfide intermediates from dissolving into liquid electrolytes [26-30]. Over the past few years, graphene has been considered an ideal host for loading active material $S$ to fabricate high-performance composite cathodes owing to unique features of graphene such as high surface area and electrical conductivity [31-39]. The graphene is usually prepared based on Hummers' oxidation and reduction method [40]. The preparation of composite cathodes involves the reduction of graphene oxide (rGO) into graphene together with $S$ loading. For instance, many researchers reported that oxygen-containing functional groups on the GO can immobilize $S$ species by chemisorption and thus improve cycling performance of the S-based cathodes [41,42]. Zhang and co-workers synthesized a layered structural composite of $\mathrm{S} /$ polypyrrole/graphene, presenting high active material S usage and cycling stability [43]. Furthermore, the S-rGO composite was synthesized through bubbling hydrogen sulfide gas into GO suspension, which can implement the GO reduction and form the graphene-S composite simultaneously [44]. Although the GO is the most commonly employed as precursor for preparing rGO and its derivatives, it usually possesses low conductivity because of the existence of a lot of oxygen-containing functional groups leading to the original sp2 hybridized network destruction. In particular, the graphene-S cathodes fabricated through different methods will not present equally electrochemical performance in Li-S battery. It is worth studying the correlation between the property of the cathodes and the fabrication approach.

Herein, we fabricate the reduced graphene oxide-S (rGO-S) composite cathodes via two common methods, i.e., one step hydrothermal and in-situ thermal reduction. The structural features and electrochemical properties in Li-S cells of the two types of asprepared rGO-S composites are studied systematically. Our investigation demonstrates that the rGO-S composites prepared by one step hydrothermal method (rGO-S-HT) have relatively better comprehensive performance as compared with the ones by in-situ thermal reduction method (rGO-S-T).

\section{Materials and Methods}

\subsection{Synthesis of Graphene Oxide (GO)}

GO was synthesized by oxidation of natural graphite powders (Sigma-Aldrich, Shanghai, China, particle size $<20 \mu \mathrm{m}$ ) referring to the modified Hummers' approaches [40]. The as-prepared GO was firstly dispersed in purified $\mathrm{H}_{2} \mathrm{O}$ and then exfoliated by 30 min ultrasonication treatment, following with a centrifugation process at 5000 r.p.m for $30 \mathrm{~min}$. Finally, the GO powders used in this work were obtained through vacuum freeze-drying technique.

\subsection{Synthesis of rGO-S Composites by One Step Hydrothermal Method (rGO-S-HT)}

The rGO-S-HT composites were prepared by one step hydrothermal method, i.e., the as-synthesized GO colloidal suspension ( $\left.5 \mathrm{~mL}, 5 \mathrm{mg} \mathrm{mL}^{-1}\right), \mathrm{Na}_{2} \mathrm{~S}_{2} \mathrm{O}_{3}(5 \mathrm{M}, 5 \mathrm{~mL})$, and $\mathrm{HCl}(1 \mathrm{M}, 3 \mathrm{~mL})$ were put into a Teflon-lined autoclave to stir for $30 \mathrm{~min}$, and then subjected to react at the ambient temperature of $180{ }^{\circ} \mathrm{C}$ for $12 \mathrm{~h}$ in vacuum oven to ensure chemical self-assembly reaction finished. The rGO-S-HT powder sample was obtained by multiple cleaning-filtration and final vacuum freeze drying. All chemical reagents used in this work were purchased from Sigma-Aldrich (Shanghai, China).

\subsection{Synthesis of rGO-S Composites by In-Situ Thermal Reduction Method (rGO-S-T)}

The rGO-S-T composites were prepared by in-situ thermal reduction method. Firstly, the as-synthesized GO powder and the pristine sublimed sulfur (Sigma-Aldrich, Shanghai, China) were weighed with a mass ratio of 2:1 and added in an agate mortar for ground milling. Then, the mixture was reactive sintered in a muffle furnace by sealing in an evacuated quartz tube with the following conditions: (i) heating up from room temperature 
to high temperature of $600{ }^{\circ} \mathrm{C}$, (ii) holding at this temperature for $6 \mathrm{~h}$, and (iii) cooling down from high temperature to room temperature at a slow rate of $0.5^{\circ} \mathrm{C} \mathrm{min}-1$. Finally, the rGO-S-T powder sample was obtained by opening the quartz tube.

\subsection{Characterizations}

The sulfur content in the composite was obtained using thermogravimetric analyzer (TGA) on a Netzsch STA 449 F1 (Selb, Germany) with the measurement conditions: (i) temperature range: $50-600^{\circ} \mathrm{C}$; (ii) heating rate: $10^{\circ} \mathrm{C} \mathrm{min}^{-1}$; and (iii) purge gas: high purity $\mathrm{N}_{2}$. The X-ray diffraction (XRD) patterns of the rGO-S and the pristine $\mathrm{S}$ samples were recorded in the 2-theta range from 10-80 using Rigaku D/max 2400 (Rigaku, Tokyo, Japan) with $\mathrm{Cu} \mathrm{K} \alpha$ radiation. The Raman spectra of samples were obtained on a dispersive Raman spectroscopic microscope (Horiba Jobin Yvon, Atlanta, GA, USA). The X-ray photoelectron spectroscopy (XPS) was carried out on an upgraded PHI-5000C ESCA system (Perkin Elmer, Hopkinton, MA, USA) with Al K $\alpha$ X-ray spectrometer at $14 \mathrm{kV}$. Scanning electron microscope (SEM) was used to observe morphology of samples on Hitachi S-4700 (Hitachi, Tokyo, Japan) operating at $10 \mathrm{kV}$, meanwhile equipped with an energy dispersive $\mathrm{X}$-ray spectrometry (EDS) (Oxford, Abingdon, UK) to characterize the elemental mapping.

\subsection{Electrode Preparation and Electrochemical Measurements}

Cathode slurry was firstly prepared by weighing the active material rGO-S composites, conductive carbon black (super P), and binder poly(vinylidene fluoride) (PVDF) with a mass ratio of 8:1:1 and adding in an agate mortar to grind for $30 \mathrm{~min}$. Then, certain volume solvent $\mathrm{N}$-methy-1-2-pyrrolidone (NMP) was added to the mixture following with magnetically stirring overnight. Finally, the electrode film was coated by casting the obtained slurry onto an aluminum foil and vacuum-oven drying at $60^{\circ} \mathrm{C}$ no less than $12 \mathrm{~h}$. The rGO-S films were cut into round pieces with a diameter of $1.2 \mathrm{~cm}$ by precision disc cutter machine, which were used as the Li-S cell electrode directly. Our fabricated electrode film contained the active material $\mathrm{S}$ of around $2 \mathrm{mg} \mathrm{cm}^{-2}$. Lithium metal was employed as the counter electrode and reference electrode, and the microporous polypropylene Celgard 3501 (Celgard, LLC Corp., Charlotte, NC, USA) as separator adopted $1.0 \mathrm{M}$ bis(trifl uoromethane) sulfonimide lithium salt (LiTFSI, Sigma-Aldrich, Shanghai, China) dissolved in a mixture of 1,3-dioxolane (DOL) and dimethoxyethane (DME) (DOL/DME, 1:1 v/v) (Sigma-Aldrich, Shanghai, China) was adopted as Li-S battery electrolyte. The coin cells were assembled in a glove box filled with high pure Ar gas. The galvanostatic charge-discharge (LAND CT 2001, Wuhan, China) and cyclic voltammetry tests (CHI660c Electrochemical Workstation, Shanghai, China) were carried out to detect electrochemical properties. The specific capacity was calculated on the basis of the active material $S$ tested by TGA measurement.

\section{Results and Discussion}

\subsection{Morphology}

SEM were conducted to observe morphology of the rGO-S composite materials. The SEM images of the rGO-S-HT and rGO-S-T are depicted in Figure 1. As shown in Figure $1 \mathrm{a}, \mathrm{b}$, it can be seen that small $\mathrm{S}$ particles were distributed uniformly on graphene layer for the rGO-S-HT sample. While for the rGO-S-T sample (see Figure 1c,d), the sheet feature structural $\mathrm{rGO}$ is also observed, but the $\mathrm{S}$ particles have more obvious aggregation. It is well known that the rGO sheets can serve as immobilizer to anchor $S$ and to protect polysulfide intermediates from dissolution into electrolytes [30-35]. Meanwhile, the S particles' distribution in graphene layers will facilitate improvement of the conductivity of the S. Moreover, the graphene possesses a robust structure with good flexibility and strength, which enables tolerating severe volume change for the $S$ during lithiation/delithiation. The EDS elemental mapping for the rGO-S-HT is also displayed in Figure 1e and $\mathrm{f}$. The $\mathrm{S}$ map follows the structure of the rGO, which suggests that the $S$ particles are well-dispersed in the rGO-S-HT composite. 


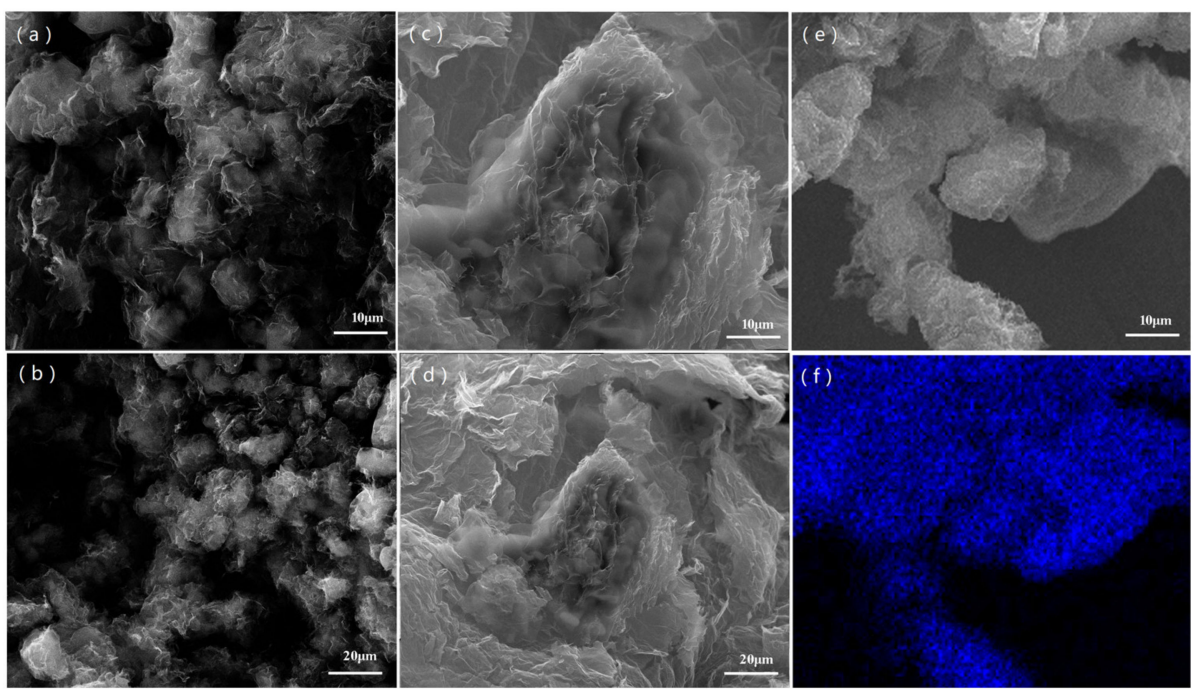

Figure 1. SEM images of rGO-S-HT $(\mathbf{a}, \mathbf{b})$, rGO-S-T $(\mathbf{c}, \mathbf{d})$, and SEM image with corresponding elemental mapping of rGO-S-HT for $\mathrm{S}(\mathbf{e}, \mathbf{f})$.

\subsection{Structural Characteristics}

Figure 2a shows the XRD patterns of S, rGO-S-HT and rGO-S-T samples. The pristine $S$ powder sample presents sharp and strong peaks curve, suggesting its typical $S_{8}$ crystal structure. For the rGO-S-T, all the diffraction peaks are almost matching with the $S$ patterns, that is, the peaks from the crystalline $S$ are obvious, which means that the $S$ deposited on the rGO sheets is mainly in form of $\mathrm{S}_{8}$ because the small $\mathrm{S}$ molecules will re-associate and finally form cyclo- $\mathrm{S}_{8}$ as the temperature cools down during the rGO-S composite preparing process by in-situ thermal reduction [33]. In contrast, the rGO-S-HT shows much weaker diffraction peak intensity than the rGO-S-T sample, which indicates that the form of $S$ is small molecular and/or amorphous. Raman spectroscopy is commonly used to characterize the graphene and other carbon materials. The Raman spectra of rGO-S-T and rGO-S-HT are shown in Figure 2b. There are two distinct peaks both for the rGO-S-T and rGO-S-HT, arising from well-known $\mathrm{G}$ and $\mathrm{D}$ bands. In addition to similar peak positions, the $\mathrm{D} / \mathrm{G}$ band intensity ratios $\left(\mathrm{I}_{\mathrm{D}} / \mathrm{I}_{\mathrm{G}}\right)$ exceed 1.0, indicating perfect degree of reduction from GO to rGO both for rGO-S-T and rGO-S-HT composite [30,31,38].
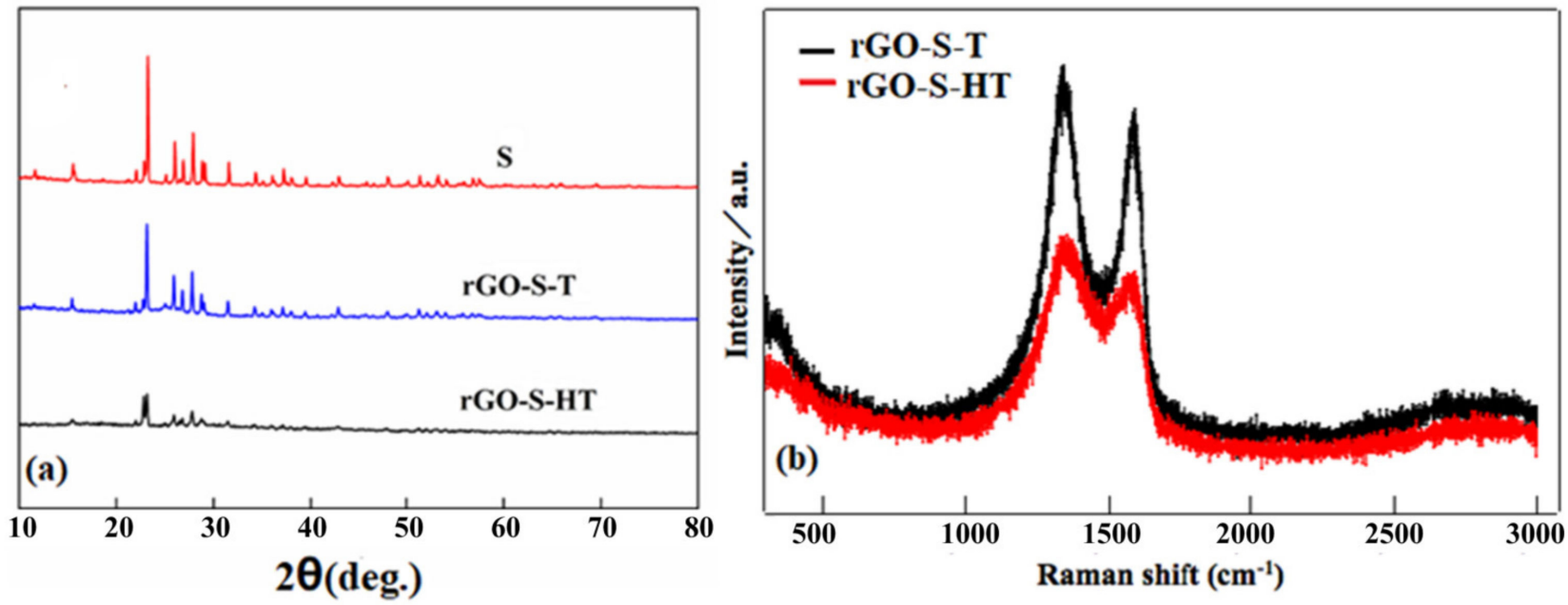

Figure 2. (a) XRD patterns of $S$, reduced graphene oxide-sulfur by in-situ thermal reduction (rGO-S-T) and rGO-S-HT (by hydrothermal method) samples, (b) Raman spectra of rGO-S-T and rGO-S-HT samples. 
The $\mathrm{S}$ contents in the rGO-S composites were tested by TGA. Figure 3 displays the TGA profile of the two composites. Around $40 \% \mathrm{~S}$ was loaded in the rGO-S-HT composite. The value is higher than that of $32 \%$ for the rGO-S-T composite. This difference demonstrates that one step hydrothermal method is more beneficial for $\mathrm{S}$ loading. In addition, it is worth noting that the onset weight loss takes place at around $120{ }^{\circ} \mathrm{C}$ for the rGO-S-T composite with the entire weight loss at approximately $300{ }^{\circ} \mathrm{C}$. This phenomenon is almost identical to the evaporation of $\mathrm{S}_{8}$. While for the rGO-S-HT composite, the TGA curve has two-step weight loss characteristic. At around $180{ }^{\circ} \mathrm{C}$, the first weight loss starts and $30 \%$ loss occurs as the temperature reaches to $300{ }^{\circ} \mathrm{C}$. The second weight loss takes place with the progressive increasing temperature from 300 to around $500{ }^{\circ} \mathrm{C}$, meanwhile, the rest of the loaded $S$ is released. This step is considered in previously reported literatures as the extraction of small molecular and/or amorphous S [28,39].

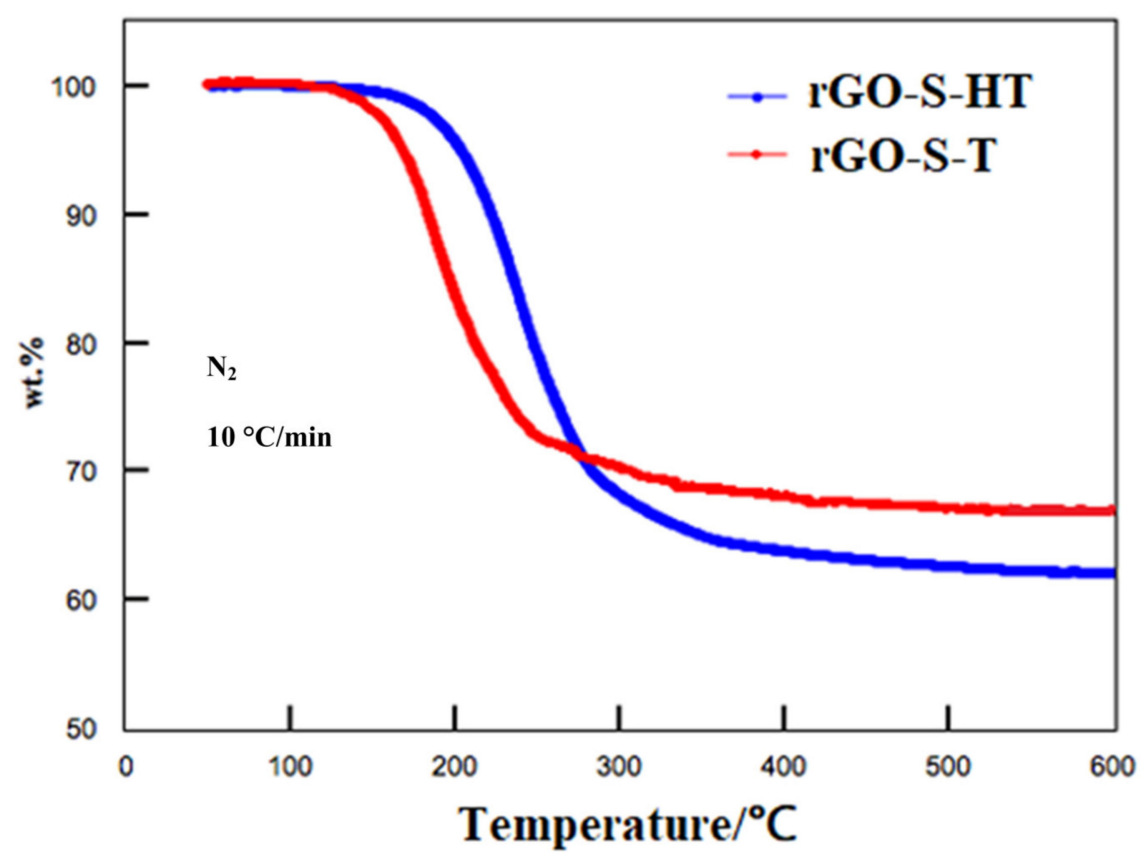

Figure 3. TGA curves of rGO-S-HT and rGO-S-T samples.

The surface chemical compositions and functional groups of the rGO-S-HT and rGO$\mathrm{S}-\mathrm{T}$ were identified by XPS technique. Figure 4 presents the $\mathrm{C} 1 \mathrm{~s}$ and $\mathrm{S} 2 \mathrm{p}$ binding energy spectra of the two composite samples. The C1s exhibits one strong peak at about $284.0 \mathrm{eV}$ for the rGO-S-HT. By further fitting, we can split the strong peak into three peaks 283.5, 284.1, and $285.2 \mathrm{eV}$, respectively, which are assigned to $\mathrm{C}-\mathrm{C}, \mathrm{C}-\mathrm{S}$, and $\mathrm{C}=\mathrm{O}$ (Figure $4 \mathrm{a}$ ). As for the rGO-S-T (Figure $4 \mathrm{~b}$ ), the $\mathrm{C} 1 \mathrm{~s}$ possesses one strong peak and a shou1der weak located at around $284.0 \mathrm{eV}$ and at $285.0 \mathrm{eV}$, respectively, which suggests the existence of C-O bonding in rGO-S-T $[45,46]$. The S $2 \mathrm{p}$ has one strong peak of around $163.0 \mathrm{eV}$ and a broad peak of $164.2 \mathrm{eV}$ both for the two rGO-S composite samples (Figure 4c,d). While for the binding energy of S2p 3/2 peak, it is located at $162.9 \mathrm{eV}$ for the two rGO-S composite samples, lower than the value of elemental $\mathrm{S}(164.0 \mathrm{eV})$, which reveals the existence of the chemical bonding between $S$ and rGO. After further fitting, the peak at $163.5 \mathrm{eV}$ can be attributed to the S-O bonds, and the peak at $164.2 \mathrm{eV}$ may be ascribed to the sulphate species formed from sulfur oxidation between $\mathrm{S}$ and oxygen functional groups of GO $[27,28,39,47]$. 

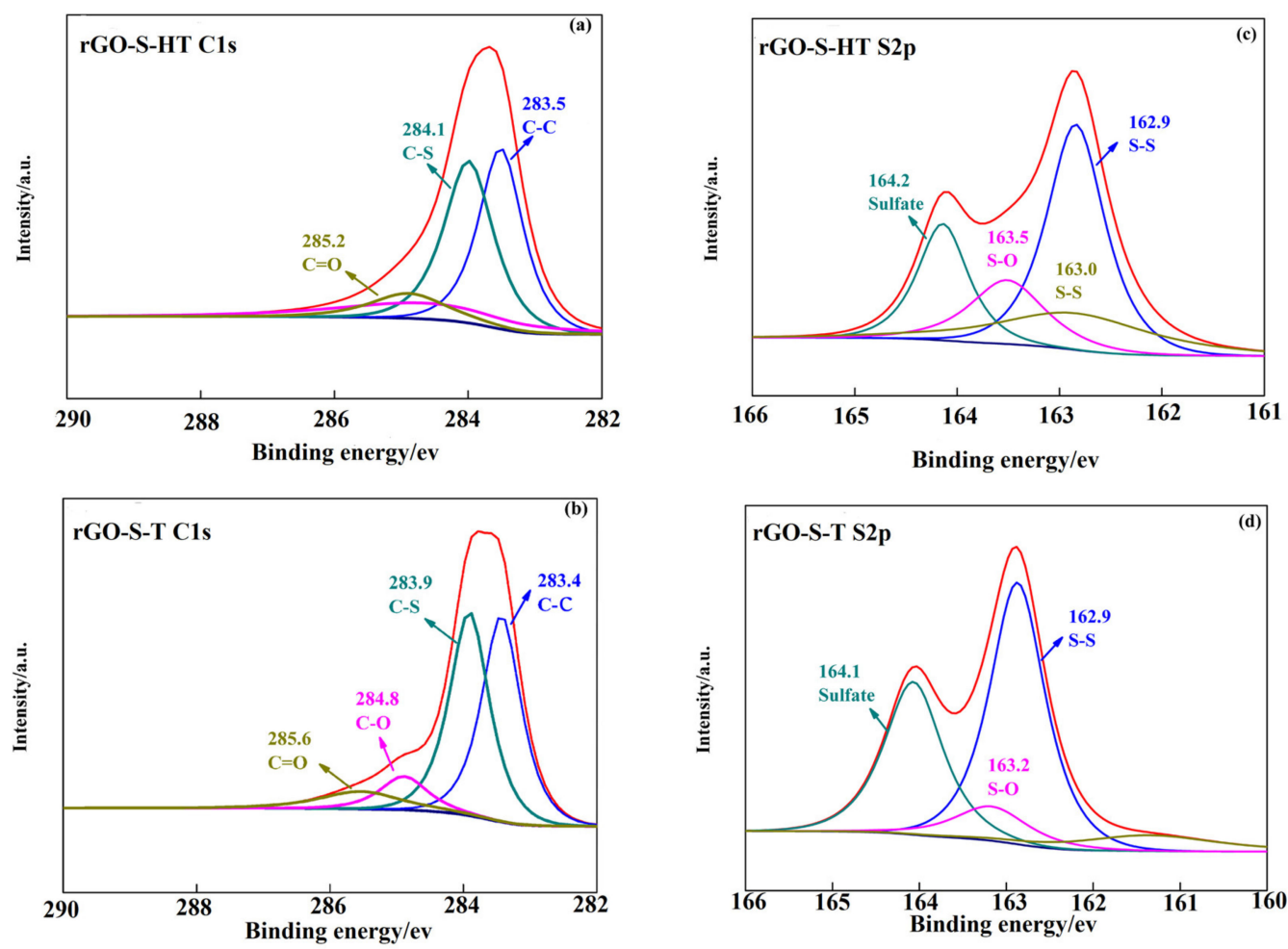

Figure 4. (a,b) C1's signal obtained from XPS spectra of rGO-S-HT and rGO-S-T, (c,d) S 2p XPS spectra of rGO-S-HT and rGO-S-T.

\subsection{Electrochemical Performance}

The electrochemical performances of the as-obtained rGO-S-HT and rGO-S-T composite cathodes for Li-S battery were tested through cyclic voltammogram $(\mathrm{CV})$ combining with galvanostatic charge/discharge measurement. Figure $5 a, b$ shows the first three cycling CV curves of the rGO-S-HT and rGO-S-T cathodes at a sweep rate of $0.1 \mathrm{mV} \mathrm{s}^{-1}$ with the potential range of $1.5-3.0 \mathrm{~V} \mathrm{vs}$. $\mathrm{Li}^{+} / \mathrm{Li}$. Two main peaks of around 2.3 and $2.0 \mathrm{~V}$ is clearly presented in the cathodic scan, ascribing to the transformation from cyclo- $\mathrm{S}_{8}$ to high-order lithium polysulfide intermediates $\left(\mathrm{Li}_{2} \mathrm{~S}_{\mathrm{n}}, 4 \leq \mathrm{n} \leq 8\right)$ and high-order lithium polysulfides into $\mathrm{Li}_{2} \mathrm{~S}_{2}$ and $\mathrm{Li}_{2} \mathrm{~S}$, respectively. While in the anodic scan, only one strong oxidation peak located around $2.4 \mathrm{~V}$ is detected, which belongs to the coupled conversion from $\mathrm{Li}_{2} \mathrm{~S}$ to lithium polysulfides $\mathrm{Li}_{2} \mathrm{~S}_{\mathrm{n}}(4 \leq \mathrm{n} \leq 8)$ and ultimately to sulfur [8,9]. In addition, slight shifts are also observed from both the reduction and oxidation peaks in the following two cycles, which related to the polarization of the cathode materials [35]. The voltage profiles of the rGO-S-HT and rGO-S-T cathodes during the 1st, 10th, 30th, 50th, 100th, and 200th cycles at a current density of $0.1 \mathrm{~A} \mathrm{~g}^{-1}$ are shown in Figure $5 \mathrm{c}$, d. From the first cyclic discharge curves, there are three voltage plateaus located at $\sim 2.3,2.1$, and $1.8 \mathrm{~V}$. They are attributed to the lithiation process of $\mathrm{S}_{8}$ to form high-order polysulfide intermediates $\left(\mathrm{Li}_{2} \mathrm{~S}_{\mathrm{n}}, 4 \leq \mathrm{n} \leq 8\right)$ and finally to produce insoluble low-order polysulfides $\mathrm{Li}_{2} \mathrm{~S}_{2}$ and/or $\mathrm{Li}_{2} \mathrm{~S}$, which is in agreement with the observed peaks in the CV (see Figure 5c). The first lithiation capacity of the rGO-S-HT cathode is around $1290 \mathrm{mAh} \mathrm{g}^{-1}$. The rGO-S-T cathode in comparison in Figure 5d, however, has the similar voltage plateaus but releases lower discharge capacity. In particular, the rGO-S-HT cathodes present better cycling stability as compared with the rGO-S-T cathode with progressive cycling. For instance, the 100th cycling discharge capacity is less than $430 \mathrm{mAh} \mathrm{g}^{-1}$ while the rGO-S-HT cathode can still deliver the capacity of $580 \mathrm{mAh} \mathrm{g}^{-1}$ even after undergoing 200 cycles. 

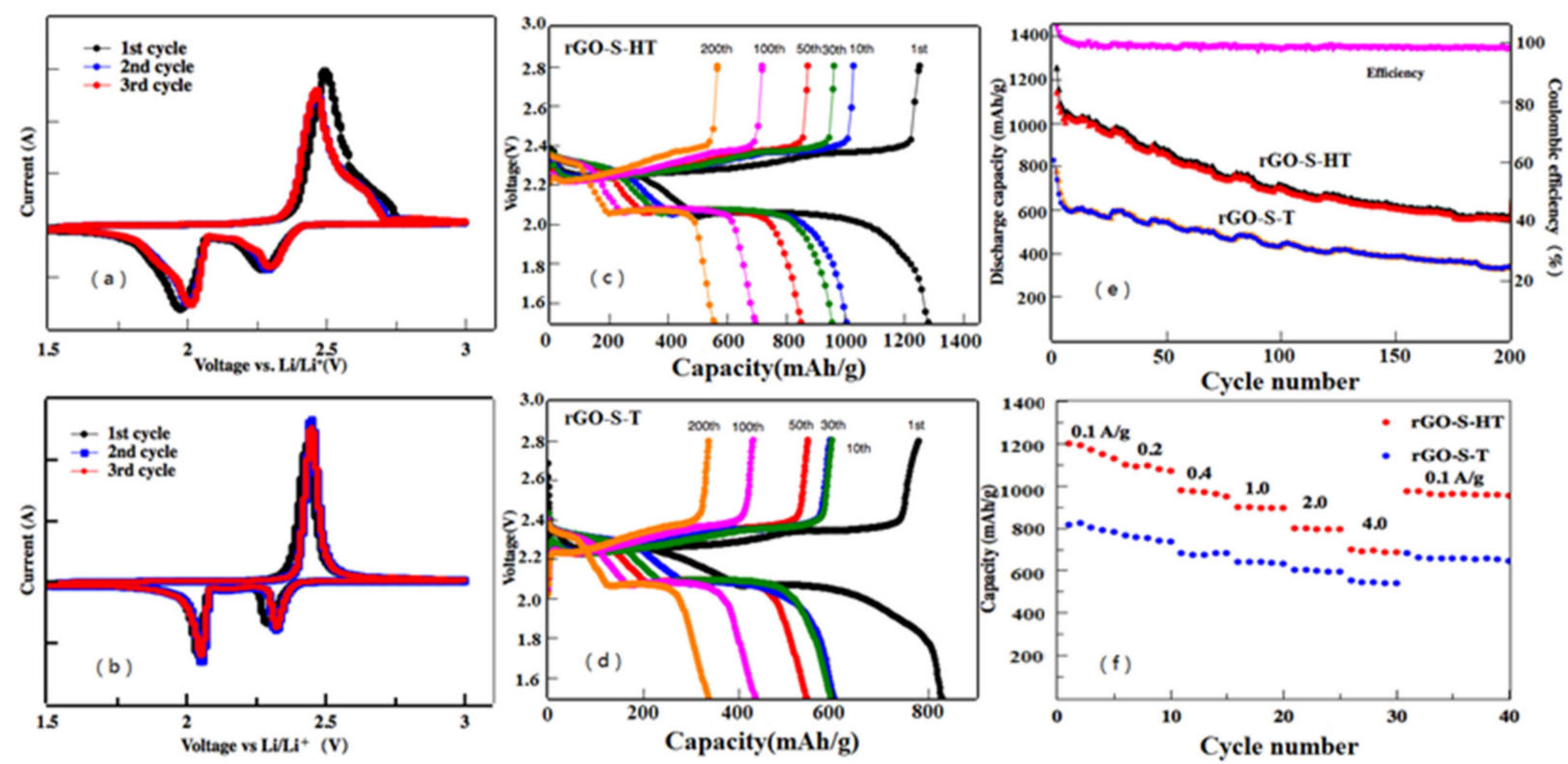

Figure 5. (a,b) Cyclic voltammograms (CVs) of the rGO-S-HT and rGO-S-T cathode at $0.1 \mathrm{mV} \mathrm{s}^{-1}$ with a potential window of 1.5-3 $\mathrm{V} \mathrm{vs} \mathrm{Li}^{+} / \mathrm{Li}$, (c,d) Discharge/charge voltage profiles of the rGO-S-HT and rGO-S-T cathode for the 1st, 50th cycles at $0.1 \mathrm{~A} \mathrm{~g}^{-1}$, (e) Cyclic performance of the rGO-S-HT and rGO-S-T cathode at $1.0 \mathrm{~A} \mathrm{~g}^{-1}$, (f) Rate performance of the rGO-S-HT and rG-S-T cathode at different current densities from 0.1 to $4.0 \mathrm{~A} \mathrm{~g}^{-1}$.

Figure 5e displays cyclic performance curve at $1.0 \mathrm{~A} \mathrm{~g}^{-1}$ for the rGO-S-HT and rGO-S-T cathodes. It can also deliver a reversible capacity of $582 \mathrm{mAh} \mathrm{g}^{-1}$ even after 200 cycles. Moreover, the Coulombic efficiency of rGO-S-HT is close to $\sim 97 \%$, demonstrating an effective limitation to the shuttling effect. By comparison, the rGO-S-T was also cycled under same electrochemical measurement conditions. It is obvious that the rGO-S-T cathode shows relatively worse cyclic lifespan than that of rGO-S-HT cathode. After 200 cycles, the capacity is less than $300 \mathrm{mAh} \mathrm{g}^{-1}$, which is almost half capacity of the rGO-S-HT. The rGO-S-HT cathode also exhibits good rate performance, as displayed in Figure $5 \mathrm{f}$. The reversible specific capacities of the first cycle are 1197, 1100, 980, 901, 817, and $719 \mathrm{mAh} \mathrm{g}^{-1}$ at $0.1,0.2,0.4$, 1,2 , and $4 \mathrm{~A} \mathrm{~g}^{-1}$ current densities, respectively, which is much higher than many of the S-based cathodes reported in the literature $[17,19,23-26]$. Furthermore, when the current density returns to $0.1 \mathrm{~A} \mathrm{~g}^{-1}$, the discharge capacity of rGO-S-HT cathode can return to 1012 $\mathrm{mAh} \mathrm{g}^{-1}$, demonstrating good electrochemical reversibility for the rGO-S-HT cathode. As for the rGO-S-T cathode, it exhibits relatively poor rate performance.

Obviously, the rGO-S composites prepared by the one-step hydrothermal method show relatively better comprehensive performance as compared with the ones by in-situ thermal reduction method, and especially, the rGO-S-HT cathodes present good cycling stability and excellent rate performance. The enhanced electrochemical properties in Li-S battery can be attributed to small S particles uniformly distributed on the rGO sheets enabling to significantly improve the conductivity of $S$ and effectively buffer large volume change during lithiation/delithiation. In addition, our results suggest that higher sulfur can be loaded in the rGO-S-HT, which is mainly related with the microstructure of the rGO due to different reduction methods. The internal mechanism will be further investigated in our future work.

\section{Conclusions}

In this work, two rGO-S composites were prepared via one step hydrothermal and insitu thermal reduction methods. The structural features and electrochemical performance in Li-S cells of the composites are studied and compared. The rGO-S composites prepared by one-step hydrothermal method show relatively better comprehensive performance as 
compared with the ones by the in-situ thermal reduction method, demonstrating good cycling stability, and excellent rate performance in Li-S battery. The uniform distribution of small S particles on the rGO sheets is the key factor, which enables to significantly improve the conductivity of $S$ and effectively buffer large volume change during lithiation/delithiation. Our results provide direct evidence that the electrochemical performance of the C-S composite electrodes for Li-S batteries are mainly related with the $S$ uniformly confined by the unique structural matrix. The related mechanisms need to be further investigated in future work.

Author Contributions: S.Z. and M.Y. conceived the idea of experiment; Z.L., H.S., and Y.P. performed the experiments; S.Z., M.Y., Z.L., H.S., and Y.P. discussed the results, and organized and edited the manuscript. All authors have read and agreed to the published version of the manuscript.

Funding: This research was funded by the Innovation Program of Shanghai Municipal Education Commission (2019-01-07-00-07-E00015) and Guangxi Key Laboratory of Information Materials (Guilin University of Electronic Technology), P.R. China (201017-K).

Institutional Review Board Statement: Not applicable.

Informed Consent Statement: Not applicable.

Data Availability Statement: The data presented in this study are available on request from the corresponding author.

Acknowledgments: We also thank Xinbo Xu for the preliminary experiment on this work during his master's study at USST.

Conflicts of Interest: Authors declare no conflict of interest.

\section{References}

1. Winter, M.; Brodd, J.R. What Are Batteries, Fuel Cells, and Supercapacitors. Chem. Rev. 2004, 104, 4245-4269. [CrossRef] [PubMed]

2. Dunn, B.; Kamath, H.; Tarascon, J.-M. Electrical Energy Storage for the Grid: A Battery of Choices. Science 2011, 334, 928-935. [CrossRef]

3. Ji, X.; Lee, K.T.; Nazar, L.F. A highly ordered nanostructured carbon-sulphur cathode forlithium-sulphur batteries. Nat. Mater. 2009, 8, 500-506. [CrossRef]

4. Yang, Y.; Zheng, G.; Cui, Y. Nanostructured sulfur cathodes. Chem. Soc. Rev. 2013, 42, 3018-3032. [CrossRef]

5. Peng, H.J.; Huang, J.Q.; Cheng, X.B.; Zhang, Q. Review on high-loading and high energy lithium-sulfur batteries. Adv. Energy Mater. 2017, 7, 1700260. [CrossRef]

6. Ji, X.; Nazar, L.F. Advances in Li-S batteries. J. Mater. Chem. 2010, 20, 9821-9826. [CrossRef]

7. Manthiram, A.; Fu, Y.; Su, Y.-S. Challenges and prospects of lithium-sulfur batteries. Acc. Chem. Res. 2013, 46, 1125-1134. [CrossRef]

8. Diao, Y.; Xie, K.; Xiong, S.; Hong, X. Analysis of polysulfide dissolved in electrolyte in discharge-charge process of Li-S battery. J. Electrochem. Soc. 2012, 159, A421-A425. [CrossRef]

9. Mikhaylik, Y.V.; Akridge, J.R. Polysulfide shuttle study in the Li/S battery system. J. Electrochem. Soc. 2004, 151, A1969-A1976. [CrossRef]

10. Song, M.K.; Cairns, E.J.; Zhang, Y. Lithium/sulfur batteries with high specific energy: Old challenges and new opportunities. Nanoscale 2013, 5, 2186-2204. [CrossRef] [PubMed]

11. Wu, F.; Lee, J.T.; Nitta, N.; Kim, H.; Borodin, O.; Yushin, G. Lithium iodide as a promising electrolyte additive for lithium-sulfur batteries: Mechanisms of performance enhancement. Adv. Mater. 2015, 27, 101-108. [CrossRef]

12. Zhang, S.; Ueno, K.; Dokko, K.; Watanabe, M. Recent advances in electrolytes for lithium-sulfur batteries. Adv. Energy Mater. 2015, 5, 201400981. [CrossRef]

13. Liu, S.; Li, G.R.; Gao, X.P. Lanthanum nitrate as electrolyte additive to stabilize the surface morphology of lithium anode for lithium-sulfur battery. ACS Appl. Mater. Interfaces 2016, 8, 7783-7789. [CrossRef] [PubMed]

14. Su, Y.-S.; Manthiram, A. Lithium-sulphur batteries with a microporous carbon paper as a bifunctional interlayer. Nat. Commun. 2012, 3, 1166. [CrossRef] [PubMed]

15. Su, Y.-S.; Manthiram, A. A new approach to improve cycle performance of rechargeable lithium-sulfur batteries by inserting a free-standing MWCNT interlayer. Chem. Commun. 2012, 48, 8817-8819. [CrossRef] [PubMed]

16. Chen, X.; Ding, X.; Wang, C.; Feng, Z.; Xu, L.; Gao, X.; Zhai, Y.; Wang, D. A multi-shelled CoP nanosphere modified separator for highly efficient Li-S batteries. Nanoscale 2018, 10, 13694-13701. [CrossRef] [PubMed]

17. Lai, Z.; Chen, Y.C.; Tan, C.; Zhang, X.; Zhang, H. Self-assembly of two-dimensional nanosheets into one-dimensional nanostructures. Chem 2016, 1, 59-77. [CrossRef] 
18. Li, Z.; Zhang, J.T.; Chen, Y.M.; Li, J.; Lou, X.W. Pie-like electrode design for high-energy density lithium-sulfur batteries. Nat. Commun. 2015, 6, 8850. [CrossRef]

19. Zhou, G.; Paek, E.; Hwang, G.S.; Manthiram, A. Long-life Li/polysulphide batteries with high sulfur loading enabled by lightweight three-dimensional nitrogen/sulphur-codoped graphene sponge. Nat. Commun. 2015, 6, 7760-7770. [CrossRef]

20. Zhang, J.; Hu, H.; Li, Z.; Lou, X.W. Double-shelled nanocages with cobalt hydroxide inner shell and layered double hydroxides outer shell as high-efficiency polysulfide mediator for lithium-sulfur batteries. Angew. Chem. 2016, 55, 3982-3986. [CrossRef]

21. Xiao, L.; Cao, Y.; Xiao, J.; Schwenzer, B.; Engelhard, M.H.; Saraf, L.V.; Nie, Z.; Exarhos, G.J.; Liu, J. A soft approach to encapsulate sulfur: Polyaniline nanotubes for lithium-sulfur batteries with long cycle life. Adv. Mater. 2012, 24, 1176-1181. [CrossRef] [PubMed]

22. Chen, R.J.; Wu, F.; Chen, J.Z.; Wu, S.X.; Li, L.; Chen, S.; Zhao, T. Sulfur/polythiophene with a core/shell structure: Synthesis and electrochemical properties of the cathode for rechargeable lithium batteries. J. Phys. Chem. 2011, 115, 6057-6063.

23. Yang, Y.; Yu, G.H.; Cha, J.J.; Wu, H.; Vosgueritchian, M.; Yao, Y.; Bao, Z.A.; Cui, Y. Improving the performance of lithium-sulfur batteries by conductive polymer coating. ACS Nano 2011, 5, 9187-9193. [CrossRef] [PubMed]

24. Wang, C.; Wan, W.; Chen, J.; Zhou, H.; Zhang, X.; Yuan, L.; Huang, Y. Dual core-shell structured sulfur cathode composite synthesized by a one-pot route for lithium sulfur batteries. J. Mater. Chem. 2013, 1, 1716-1721. [CrossRef]

25. Li, G.; Li, G.; Ye, S.; Gao, X. A polyaniline-coated sulfur/carbon composite with an enhanced high-rate capability as a cathode material for lithium/sulfur batteries. Adv. Energy Mater. 2012, 2, 1238-1245. [CrossRef]

26. Li, Z.; Zhang, J.; Lou, X.W. Hollow carbon nanofibers filled with $\mathrm{MnO}_{2}$ nanosheets as efficient sulfur hosts for lithium-sulfur batteries. Angew. Chem. 2015, 54, 12886-12890. [CrossRef]

27. Zheng, G.; Yang, Y.; Cha, J.J.; Hong, S.S.; Cui, Y. Hollow Carbon nanofiber-encapsulated sulfur cathodes for high specific capacity rechargeable lithium batteries. Nano Lett. 2011, 11, 4462-4467. [CrossRef]

28. Zheng, S.; Chen, Y.; Xu, Y.; Yi, F.; Zhu, Y.; Liu, Y.; Yang, J.; Wang, C. In situ formed lithium sulfide/microporous carbon cathodes for lithium-ion batteries. ACS Nano 2013, 7, 10995-11003. [CrossRef]

29. Liang, C.D.; Dudney, N.J.; Howe, J.Y. Hierarchically structured sulfur/carbon nanocomposite material for high-energy lithium battery. Chem. Mater. 2009, 21, 4724-4730. [CrossRef]

30. Yoo, E.; Kim, J.; Hosono, E.; Zhou, H.S.; Kudo, T.; Honma, I. Large reversible Li storage of graphene nanosheet families for use in rechargeable lithium ion batteries. Nano Lett. 2008, 8, 2277-2282. [CrossRef] [PubMed]

31. Zhao, C.; Yu, C.; Liu, S.; Yang, J.; Fan, X.; Huang, H.; Qiu, J. 3D porous n-doped graphene frameworks made of interconnected nanocages for ultrahigh-rate and long-life $\mathrm{Li}_{2} \mathrm{O}_{2}$ batteries. Adv. Funct. Mater. 2015, 25, 6913-6920. [CrossRef]

32. Zhang, Z.; Wang, G.; Lai, Y.; Li, J. A freestanding hollow carbon nanofiber/reduced graphene oxide interlayer for highperformance lithium-sulfur batteries. J. Alloys Compd. 2016, 663, 501-506. [CrossRef]

33. Jiang, Y.; Lu, M.; Ling, X.; Jiao, Z.; Chen, L.; Hu, P.; Zhao, B. One-step hydrothermal synthesis of three-dimensional porous graphene aerogels/sulfur nanocrystals for lithium-sulfur batteries. J. Alloys Compd. 2015, 645, 509-516. [CrossRef]

34. Li, S.; Cen, Y.; Xiang, Q.; Aslam, M.K.; Hu, B.; Li, W.; Tang, Y.; Yu, Q.; Liu, Y.; Chen, C. Vanadium dioxide-reduced graphene oxide binary host as an efficient polysulfide plague for high-performance lithium-sulfur batteries. J. Mater. Chem. 2019, 7, 1658-1668. [CrossRef]

35. Zhang, Y.; Wang, R.; Tang, W.; Zhan, L.; Zhao, S.; Kang, Q.; Wang, Y.; Yang, S. Efficient polysulfide barrier of a graphene aerogel-carbon nanofibers-Ni network for high-energy-density lithium-sulfur batteries with ultrahigh sulfur content. J. Mater. Chem. 2018, 10, 20926-20938. [CrossRef]

36. Zhang, J.; Yang, N.; Yang, X.; Li, S.; Yao, J.; Cai, Y. Hollow sulfur@graphene oxide core-shell composite for high-performance Li-S batteries. J. Alloys Compd. 2015, 650, 604-609. [CrossRef]

37. Zu, C.; Manthiram, A. Hydroxylated graphene-sulfur nanocomposites for high-rate lithium-sulfur batteries. Adv. Energy Mater. 2013, 3, 1008-1012. [CrossRef]

38. Sun, Y.; Zheng, G.; She, Z.W.; Liu, N.; Wang, S.; Sun, J.; Lee, H.R.; Cui, Y. Graphite-encapsulated Li-metal hybrid anodes for high-capacity Li batteries. Chem 2016, 2, 287-297. [CrossRef]

39. Zheng, S.Y.; Wen, Y.; Zhu, Y.; Han, Z.; Wang, J.; Yang, J.; Wang, C. In situ sulfur reduction and intercalation of graphite oxides for Li-S battery cathodes. Adv. Energy Mater. 2015, 4, 1400482. [CrossRef]

40. Hummers, W.S.; Offeman, R.E. Preparation of graphitic oxide. J. Am. Chem. Soc. 1958, 80, 1339. [CrossRef]

41. Zhang, J.; Li, J.; Wang, W.; Zhang, X.; Tan, X.; Chu, W.; Guo, Y. Microemulsion assisted assembly of 3D porous S/graphene@g$\mathrm{C}_{3} \mathrm{~N}_{4}$ hybrid sponge as free-standing cathodes for high energy density Li-S batteries. Adv. Energy Mater. 2018, 8, 1702839. [CrossRef]

42. Kaiser, M.R.; Ma, Z.; Wang, X.; Han, F.; Gao, T.; Fan, X.; Wang, J.Z.; Liu, H.K.; Dou, S.; Wang, C. Reverse microemulsion synthesis of sulfur/gaphene composite for lithium/sulfur batteries. ACS Nano 2017, 11, 9048-9056. [CrossRef]

43. Zhang, Y.; Zhao, Y.; Konarov, A.; Gosselink, D.; Soboleski, H.G.; Chen, P. A novel nano-sulfur/polypyrrole/graphene nanocomposite cathode with a dual-layered structure for lithium rechargeable batteries. J. Power Sour. 2013, 241, 517-521. [CrossRef]

44. Zhang, C.; Lv, W.; Zhang, W.; Zheng, X.; Wu, M.; Wei, W.; Tao, Y.; Li, Z.; Yang, Q. Reduction of graphene oxide by hydrogen sulfide: A promising strategy for pollutant control and as an electrode for Li-S batteries. Adv. Energy Mater. 2014, 4, 175-182. [CrossRef] 
45. Ji, L.; Rao, M.; Zheng, H.; Zhang, L.; Li, Y.; Duan, W.; Guo, J.; Cairns, E.J.; Zhang, Y. Graphene oxide as a sulfur immobilizer in high performance lithium/sulfur cells. J. Am. Chem. Soc. 2011, 133, 18522-18527. [CrossRef]

46. Wang, Z.; Dong, Y.; Li, H.; Zhao, Z.; Bin, W.H.; Hao, C.; Liu, S.; Qiu, J.; Lou, X.W. Enhancing lithium-sulphur battery performance by strongly binding the discharge products on amino-functionalized reduced graphene oxide. Nat. Commun. 2014, 5, 5002-5008. [CrossRef] [PubMed]

47. Benitez, A.; Di Lecce, D.; Elia, G.A.; Caballero, A.; Morales, J.; Hassoun, J. A lithiumion battery using a 3D-array nanostructured graphene-sulfur cathode and a silicon oxide-based anode. ChemSusChem 2018, 11, 1512-1520. [CrossRef] [PubMed] 